\title{
Preparation of 100-160-nm-Sized Branched Palladium Islands with Enhanced Electrocatalytic Properties on HOPG
}

\author{
Y. Gimeno, ${ }^{\dagger}$ A. Hernández Creus,${ }^{\dagger}$ S. González, ${ }^{\dagger}$ R. C. Salvarezza, ${ }^{\ddagger}$ and \\ A. J. Arvia*,‡ \\ Departamento de Química Física, Universidad de La Laguna, La Laguna, Tenerife, Spain, \\ and Instituto de Investigaciones Fisicoquímicas Teóricas y Aplicadas (INIFTA), Universidad \\ Nacional de La Plata, Consejo Nacional de Investigaciones Científicas y Técnicas, Sucursal 4 , \\ Casilla de Correo 16, (1900) La Plata, Argentina
}

Received January 8, 2001. Revised Manuscript Received March 15, 2001

\begin{abstract}
A method for the preparation of stable 100-160-nm-sized quasi-2D branched palladium islands on highly oriented pyrolitic graphite (HOPG) is described. This type of island is electrodeposited from an aqueous acidic palladium chloride solution containing an excess of sodium perchlorate at potentials just a few millivolts above the threshold potential of the hydrogen evolution reaction. Each branched palladium island consists of a central 3D core and large quasi-2D branches that form a dense radial pattern. In contrast to massive palladium, branched islands exhibit enhanced electrocatalytic properties for the hydrogen atom electroadsorption/electrodesorption reaction and the electrooxidation reaction of hydrazine. This enhancement is mainly related to the fractal characteristics of branched palladium islands on HOPG.
\end{abstract}

\section{Introduction}

Nanometer-sized particles are of increasing importance in surface science, particularly in heterogeneous catalysis. ${ }^{1-3}$ Small metal particles play a key role in electrocatalytic reactions such as hydrogenation, hydroformylation, carbonylation and so on. ${ }^{4}$ The catalytic efficiency of small-sized metal particles depends on the electronic interaction between the small metal particles and the reactant molecules and the surface-to-volume ratio of the small metal particles. In general, for particle sizes on the order of $100 \mathrm{~nm}$ or lower, surface effects become of increasing importance, and the material properties depart from those of the massive material. ${ }^{3-5}$ Catalysis based on small metal particles occurs on solid porous matrixes that are usually made of carbon or polymeric materials as particle dispersing media. In general, the activity of these catalysts tends to decrease with time because of particle sintering, ${ }^{6}$ although this process can be reasonably controlled by using proper materials with a design suitable for technical applications. ${ }^{7}$

Carbon-supported palladium catalysts are of interest for a number of heterogeneous chemical hydrogenation,

* Author to whom correspondence should be addressed. Tel.: 54 221-4257430,54-221-4257291. Fax: 54-221-4254642.E-mail: ajarvia@ inifta.unlp.edu.ar.

${ }^{\dagger}$ Universidad de La Laguna.

‡ Universidad Nacional de La Plata (INIFTA).

(1) Somorjai, G. A. Introduction to Surface Chemistry and Catalysis; John Wiley \& Sons: New York, 1994.

(2) Memmel, N. Surf. Sci. Rep. 1998, 32, 91

(3) Henry, C. R. Appl. Surf. Sci. 2000, 164, 252.

(4) Li, F.; Wang, E.; Dong, S. J. Electroanal. Chem. 1997, 422, 27.

(5) Che, M.; Benett, C. O. Adv. Catal. 1997, 36, 27.

(6) Bonzel, H. P. In Surface Physics of Materials; Blakeley, J. M., Ed.; Academic Press: New York, 1975; p 280. oxidation, and electrocatalytic reactions and also because of their increased sensitivity to electroanalytical reactions. ${ }^{8}$ The catalytic activity of palladium deposits is determined by the influence of structural characteristics on sorption processes at different scales, which in turn depend on the growth mode of the deposit.

Palladium-modified carbon electrodes are usually prepared by the soaking of carbon in palladiumcompound-containing solutions, followed by adequate baking for the reduction of the palladium compound to palladium; by vapor-phase palladium deposition; and by electrodeposition from a palladium plating solution. ${ }^{9} \mathrm{It}$ has been shown that the sorptive and catalytic properties of palladium electrodeposits on platinum and the composition of the $\alpha$-phase palladium hydride on platinum and carbon depend on the electrodeposition potential, ${ }^{10-14}$ particularly when the phase growth is accompanied by deep hydrogenation of palladium. ${ }^{14}$

(7) Hirschenhofer, R. R.; Stauffer, D. B.; Engleman, R. R.; Klett M. G. Fuel Cell Handbook, 4th ed.; U.S. Department of Energy, Office of Fossil Energy, Federal Energy Technology Center: Morgantown, New York, 1998.

(8) Heinz, K.; Guttmann, M.; Beyer, L. J. Electroanal. Chem. 1999 462, 174 .

(9) Cleghorn, S. J. C.; Pletcher, D. Electrochim. Acta 1993, 28, 425 Cai, X.; Kalcher, K.; Litschinger, J.; Neuhold, Ch.; Zykarski, J.; Ogorevc, B. Electroanalysis 1995, 7, 556. Zhang, X. G.; Murakami, Y.; Yahikosawa, K.; Takasu, Y. Electrochim. Acta 1997, 42, 223.

(10) Podlovchenko, B. I.; Petukhova, R. P.; Kolyadko, E. E.; Lifshits, A. D. Elektrokhimiya 1976, 12, 813.

(11) Gamburg, Yu. D.; Petukhova, R. P.; Lifshits, A. D.: Pod lovchenko, B. I.; Polukarov, Yu. M. Sov. Electrochem. 1979, 15, 1875

(12) Kolyadko, E. E.; Shigan, Lu; Podlovchenko, B. I. Elektrokhimiya 1992, 28, 385.

(13) Podlovchenko, B. I.; Kolyadko, E. E.; Shigan, L. J. Electroanal. Chem. 1995, 399, 21.

(14) Rusanova, M. Yu.; Tsirlina, G. A.; Petrii, O. A.; Safonova, T. Ya.; Vasil'ev, S. Yu. Russ. J. Electrochem. 2000, 36, 457. 
Therefore, it is important to establish the range of those parameters relevant to the controlled production of nanostructures of palladium that could be applicable to catalysis and electrocatalysis.

In this work we describe an electrochemical method for producing nanometer-sized palladium islands on the surface of highly oriented pyrolytic graphite (HOPG). For this purpose, an aqueous acidic palladium chloride solution containing an excess of sodium perchlorate is used. Branched palladium islands on HOPG are produced in the potential range below the threshold potential of the hydrogen evolution reaction by a nucleation and growth process under diffusion control from the solution side. The electrocatalytic properties of these islands are explored using two test reactions under cyclic voltammetry conditions, namely, the electroadsorption/electrodesorption of hydrogen and the electrooxidation of hydrazine in aqueous solution at 298 $\mathrm{K}$. The first reaction, which is not directly observed for massive palladium, is an electrochemical surface reaction, the contribution of which is remarkably enhanced at branched palladium islands on HOPG. The second reaction, a typical electrocatalytic oxidation reaction under mixed kinetics, exhibits a considerable decrease in the anodic overpotential when it occurs on the surface of branched palladium island electrodes. From scanning tunneling microscopy imaging and electrochemical data for test reactions on these electrodes, it is possible to explain the electrocatalytic efficiency in terms of the distribution of local electronic properties resulting from the fractal perimeter of the nanometer-sized palladium islands.

\section{Experimental Section}

Experiments consisted of (i) the preparation of branched palladium islands on HOPG; (ii) the characterization of palladium electrodeposits by scanning tunneling microscopy (STM); and (iii) the determination of their electrocatalytic properties.

Palladium was electrodeposited on a freshly exfoliated HOPG working electrode (geometric area $=0.55 \mathrm{~cm}^{2}$ ) from an aqueous mixture of $7.5 \times 10^{-4} \mathrm{M}$ palladium chloride, $5 \times 10^{-2}$ $\mathrm{M}$ sodium perchlorate, and $5 \times 10^{-3} \mathrm{M}$ perchloric acid. For this purpose, a conventional glass electrochemical cell, provided with a palladium counter electrode and a saturated calomel reference electrode, was used. The working conditions for establishing the optimal growth mode for the branched palladium islands were evaluated from a cathodic polarization curve run between $0.8 \mathrm{~V}$ and the threshold potential for the hydrogen evolution reaction (HER). The working solution was prepared from analytical reagent-grade chemicals and MilliQ* Millipore water. It was deaerated by bubbling with purified argon prior to each electrochemical run.

Palladium islands were grown by stepping the potential from $E_{\mathrm{i}}=0.7 \mathrm{~V}$ to a value of $E_{\mathrm{d}}$ set in the range $-0.35 \mathrm{~V} \leq E_{\mathrm{d}}$ $\leq 0.15 \mathrm{~V}$. The electrodeposition time was in the range $10 \mathrm{~s} \leq$ $t_{\mathrm{d}} \leq 650 \mathrm{~s}$, and the electrodeposition charge density, which was measured with a digitalized coulometer, was in the range $1 \mathrm{mC} \mathrm{cm}-2 \leq q_{\mathrm{d}} \leq 5 \mathrm{mC} \mathrm{cm}{ }^{-2}$. These values are referred to the geometric area of the HOPG substrate.

STM imaging proceeded after the HOPG working electrode was removed from the electrochemical cell, carefully rinsed by immersion in water for $2 \mathrm{~min}$, and finally dried under argon at room temperature. Subsequently, images were obtained using a Nanoscope IIE STM (Digital Instruments, Santa Barbara, CA) using Pt-Ir Nanotips operating in air. Because of the stability of both palladium electrodeposits and HOPG in air, the morphology of the deposits could be analyzed ex situ by setting the tunelling current in the range $0.5-0.8 \mathrm{nA}$ and the bias voltage in the range $0.5-1.0 \mathrm{~V}$. Images were taken at a low rate, usually on the order of $0.8 \mathrm{~Hz}$ for images $5 \times 5$ $\mu \mathrm{m}^{2}$ in size, to avoid either damage to the deposit or its removal by the tip. Scanning electron microscopy (SEM) images of palladium electrodeposits were also obtained.

For the characterization of the electrocatalytic properties of palladium islands, two test reactions were selected, namely, the hydrogen atom electroadsorption/electrodesorption reaction on palladium and the electrooxidation reaction of hydrazine. The first reaction is a surface electrochemical reaction that occurs on noble metal electrocatalysts, such as platinum ${ }^{15}$ and activated palladium. ${ }^{16}$ This reaction is of interest for a number of electroreduction and electrooxidation processes, particularly in aqueous environments. The second reaction can be taken as a model for the electrooxidation of organics under intermediate kinetics. ${ }^{17,18}$ Both reactions were followed by conventional cyclic voltammetry at $v=0.1$ and $0.2 \mathrm{~V} \mathrm{~s}^{-1}$, at $298 \mathrm{~K}$, utilizing a palladium wire $\left(0.125 \mathrm{~cm}^{2}\right.$ geometric area) and palladium electrodeposits built up by electrodepositing $q_{\mathrm{d}}=5$ $\mathrm{mC} \mathrm{cm}^{-2}$ on HOPG under two different growth modes, namely, as a quasi-hemispherical or branched electrodeposit covering a fraction of the HOPG surface.

Data for the hydrogen electrosorption reactions were obtained from aqueous $0.1 \mathrm{M}$ perchloric acid, whereas for the electrooxidation of hydrazine, an aqueous mixture of $6 \times 10^{-3}$ $\mathrm{M}$ hydrazinium sulfate and $0.1 \mathrm{M}$ potassium sulfate was used. These solutions were first deareated and kept under argon during the experiments.

\section{Results}

3.1. Polarization Curve. The composition of the working solution implies that palladium species are aqueous $\mathrm{Pd}^{2+}$ and chloride-containing palladium complexes of the type $\left(\mathrm{PdCl}_{n}\right)^{2-n}$ with $n=1-4 .{ }^{20}$ The equilibrium constants of reactions $n \mathrm{Cl}^{-}+\mathrm{Pd}^{2+}=$ $\left(\mathrm{PdCl}_{n}\right)^{2-n}$ are $\beta_{1}=4.47, \beta_{2}=7.74, \beta_{3}=10.2$, and $\beta_{4}=$ 11.5 at $298 \mathrm{~K} .{ }^{19,20}$ The reversible electrode potentials for the reactions $\left(\mathrm{PdCl}_{n}\right)^{2-n}+2 \mathrm{e}^{-}=\mathrm{Pd}^{0}+n \mathrm{Cl}^{-}$, calculated for the equilibrium concentration of each species (vs SCE), are $E_{\mathrm{r} 1}=0.528 \mathrm{~V}, E_{\mathrm{r} 2}=0.491 \mathrm{~V}, E_{\mathrm{r} 3}$ $=0.493 \mathrm{~V}$, and $E_{\mathrm{r} 4}=0.640 \mathrm{~V}$. The equilibrium concentration of the chloride and palladium ions are $4.13 \times$ $10^{-4} \mathrm{M}$ and $3.16 \times 10^{-5} \mathrm{M}$, respectively. Correspondingly, $E_{\mathrm{r}}\left(\mathrm{Pd}^{2+} / \mathrm{Pd}^{0}\right)=0.526 \mathrm{~V}$.

A typical polarization curve for a HOPG electrode in an aqueous mixture of $7.5 \times 10^{-4} \mathrm{M}$ palladium chloride, $5 \times 10^{-2} \mathrm{M}$ sodium perchlorate, and $5 \times 10^{-3} \mathrm{M}$ perchloric acid run at $5 \times 10^{-3} \mathrm{~V} \mathrm{~s}^{-1}$ from 0.8 to -0.4 $\mathrm{V}$, plotted as current density $(j)$ vs applied potential $(E)$, is shown in Figure 1. This plot covers three different potential regions (I, II, and III). Region I extends from 0.8 to ca. $0.35 \mathrm{~V}$. It exhibits an appreciable cathodic polarization, and the cathodic current tends to attain a first plateau that is principally related to the discharge of aqueous $\mathrm{PdCl}_{2}$ and $\mathrm{PdCl}_{3}{ }^{-}$ion to $\mathrm{Pd}^{0}$. Region II starts

(15) Adzic, R. In Modern Aspects of Electrochemistry, White, R. W., Bockris, J. O’M., Conway, B. E., Eds.; Plenum Press: New York, 1990; Vol. 21, p 163

(16) Andreasen, G.; Visintin, A.; Salvarezza, R. C.; Triaca, W. E.; Arvia, A. J. Langmuir 1999, 15, 1.

(17) Plieth, W. J. In Encyclopedia of the Electrochemistry of the Elements; Bard, A. J., Ed.; Marcel Dekker: New York, 1978; Vol. VIII, Chapter 5, p 354 and references therein.

(18) Gómez, R.; Orts, J. M.; Rodes, A.; Feliú, J. M.; Aldaz, A. J. Electroanal. Chem. 1993, 358, 287.

(19) Standard Potentials in Aqueous Solution, Bard, A. J., Parsons, R., Jordan, J., Eds.; IUPAC, Marcel Dekker: New York, 1985.

(20) Smith. R. M.; Martell, A. R. Critical Stability Constants; Plenum Press: New York, 1976; Vol. 4, p 107. 


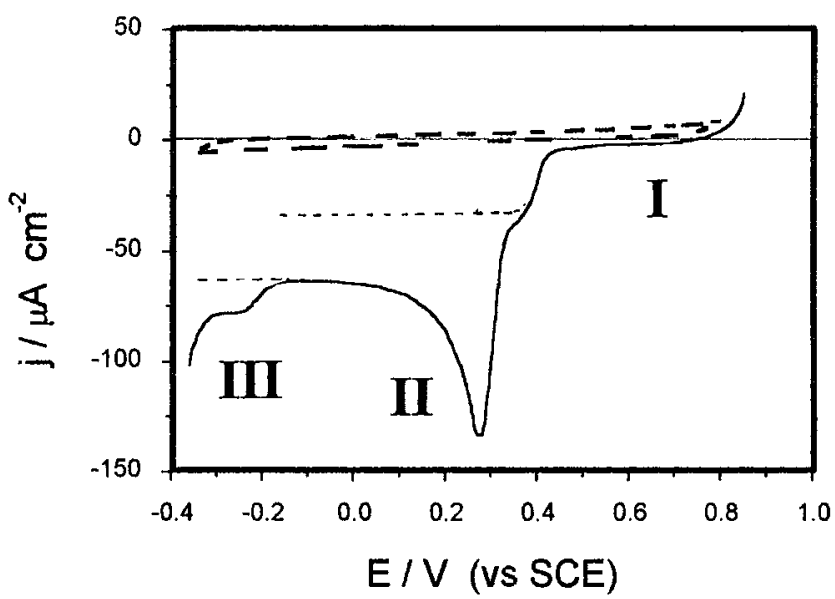

Figure 1. Apparent current density $(j)$ referred to the HOPG geometric area vs potential $(E)$ plot for palladium electrodeposition on HOPG, from an aqueous mixture of $7.5 \times 10^{-4} \mathrm{M}$ palladium chloride, $5 \times 10^{-2} \mathrm{M}$ sodium perchlorate, and $5 \times$ $10^{-3} \mathrm{M}$ perchloric acid, run at $5 \times 10^{-3} \mathrm{~V} / \mathrm{s}$ and $298 \mathrm{~K}$. Regions I, II, and III are described in the text. Cathodic limiting currents, related to palladium electrodeposition from different species in solution, are indicated by dashed traces. The dotted line corresponds to the polarization curve on HOPG in a mixture of $5 \times 10^{-2} \mathrm{M}$ sodium perchlorate and $5 \times 10^{-3} \mathrm{M}$ perchloric acid (blank).

at ca. $0.35 \mathrm{~V}$. It shows a diffusional current hump that extends between 0.3 and $0 \mathrm{~V}$ and is followed by a second plateau when the concentration of reactants at the electrode surface approaches zero. The height ratio between the first and second cathodic current plateau is close to one, as expected from the composition of the working solution. Finally, region III from $-0.2 \mathrm{~V}$ downward, comprising a cathodic wave, is related to the contribution of HER on palladium ${ }^{21}$ occurring simultaneously with palladium electrodeposition. The HER reaction on palladium is a complex electrochemical reaction that depends considerably on the surface morphology, as discussed later. The preceding voltammetric description was confirmed by running blank experiments in the absence of soluble palladium ions in the solution (Figure 1, dashed trace). Further kinetic details of those three processes will be discussed elsewhere. ${ }^{22}$

3.2. STM Imaging. STM images of palladium deposits built up in the potential regions I, II, and III show quite different morphologies. In general, for a constant value of $q_{\mathrm{d}}$, the more positive the value of $E_{\mathrm{d}}$, the more quasi-spherical islands are obtained.

Branched islands of palladium on HOPG are obtained for values of $E_{\mathrm{d}}$ in the range of region II just preceding the initiation of the HER. Thus, STM images at $E_{\mathrm{d}}=$ $-0.100 \mathrm{~V}$ for $q_{\mathrm{d}}=3 \mathrm{mC} \mathrm{cm}^{-2}$ (Figure 2a) show the presence of a large number of overlapping tiny islands preferentially nucleated at step edges and others randomly distributed on HOPG terraces. The average diameter of these islands is about $100-160 \mathrm{~nm}$. At a higher resolution (Figure $2 \mathrm{~b}$ ), we can observe that each island consists of a small central 3D core, $20 \mathrm{~nm}$ in height, surrounded by quasi-2D dendritic branches with

(21) Salvarezza, R. C.; Montemayor, R. C.; Fatas, E.; Arvia, A. J. J. Electroanal. Chem. 1991, 313, 291.

(22) Gimeno, Y.; Hernández Creus, A.; González, S.; Salvarezza, R. C.; Arvia, A. J., manuscript in preparation. a preferred orientation on the HOPG surface. Most islands show that the main branches merge at $120^{\circ}$ from the central core, resulting in a triangular island shape that is consistent with a (111) metallic lattice. Secondary branches emerging from the main branch produce a dense growth pattern, with these branches separated by thin fjords that are $10 \mathrm{~nm}$ in width. These island patterns closely resemble the dense radial morphologies exhibiting nonfractal masses and self-affine fractal perimeters, as have been observed for several metallic electrodeposits. ${ }^{23}$ The density of palladium islands $(N)$ on HOPG terraces depends only slightly on $t_{\mathrm{d}}$, i.e., the value of $N$ increases from $(5 \pm 0.5) \times 10^{9}$ to $(6 \pm 0.6) \times$ $10^{9} \mathrm{~cm}^{-2}$ as $q_{\mathrm{d}}$ is increased from 1 to $5 \mathrm{mC} \mathrm{cm}^{-2}$.

The cross section resulting from STM images taken along the main branching direction from the core border down to the branch tip (Figure 2c) corresponds to atomically smooth terraces separated by monatomic height steps, approaching the profile of a 2D pattern. The branch height decreases by only about $5 \mathrm{~nm}$ in going from the core border to the tip, with an average slope close to $3-4^{\circ}$. The typical branch tip radius is close to $10 \mathrm{~nm}$, and the tip height fluctuates between 2 and $4 \mathrm{~nm}$.

Palladium electrodeposition at $E_{\mathrm{d}}=0.150 \mathrm{~V}$ (region II) for $q_{\mathrm{d}}=3 \mathrm{mC} \mathrm{cm}-2$ produces quasi-hemispherical islands (Figure 3 ) that consist of either a single island or clusters of quasi-hemispherical islands appearing as bright and faint circular spots (Figure 3a). SEM micrographs (Figure $3 \mathrm{~b}$ ) confirm the morphology shown in the STM images, allowing us to discard tip-induced artifacts. This micrograph also shows a narrow distribution of clusters of 100-200 $\mathrm{nm}$ in average size. The number of islands per cluster varies between 1 and 4 . Further details of these islands are obtained from higher-resolution STM images (Figure 3c). These images show that each single island is about $100 \mathrm{~nm}$ in diameter and 35-40 $\mathrm{nm}$ in height. They also reveal that each single quasi-hemispherical island consists of a grained surface formed by the aggregation of small subunits that are $10 \mathrm{~nm}$ in size.

3.3. Voltammetry of Electrocatalytic Test Reactions. We studied the reactivity of nanometer-sized quasi-hemispherical and branched palladium islands for the hydrogen atom electroadsorption/electrodesorption reactions in aqueous $0.1 \mathrm{M}$ perchloric acid by cyclic voltammetry at $0.1 \mathrm{~V} \mathrm{~s}^{-1}$ covering the potential range $0.3 \mathrm{~V} \leq E \leq-0.3 \mathrm{~V}$. For the sake of comparison, the same experiments were also run with massive palladium and massive platinum polycrystalline electrodes.

In agreement with previously published results, ${ }^{16}$ the voltammogram resulting from massive palladium (Figure $4 \mathrm{a})$, for $E$ between 0 and $-0.3 \mathrm{~V}$, shows a cathodic current essentially related to the absorption of hydrogen on palladium, together with the initial formation of molecular hydrogen. The reverse potential sweep shows the electrooxidation of absorbed hydrogen as the main contribution to the anodic current, with a broad anodic current peak at $-0.075 \mathrm{~V}$. This voltammogram shows no traces of adsorbed hydrogen, either for the cathodic potential limit at $-0.30 \mathrm{~V}$ or for $-0.15 \mathrm{~V}$ (Figure $4 \mathrm{a}$, inset). Therefore, in contrast to the voltammogram of

(23) Barabási, A. L.; Stanley, H. E. Fractal Concepts in Surface Growth; Cambridge Universy Press: New York, 1995. 
a

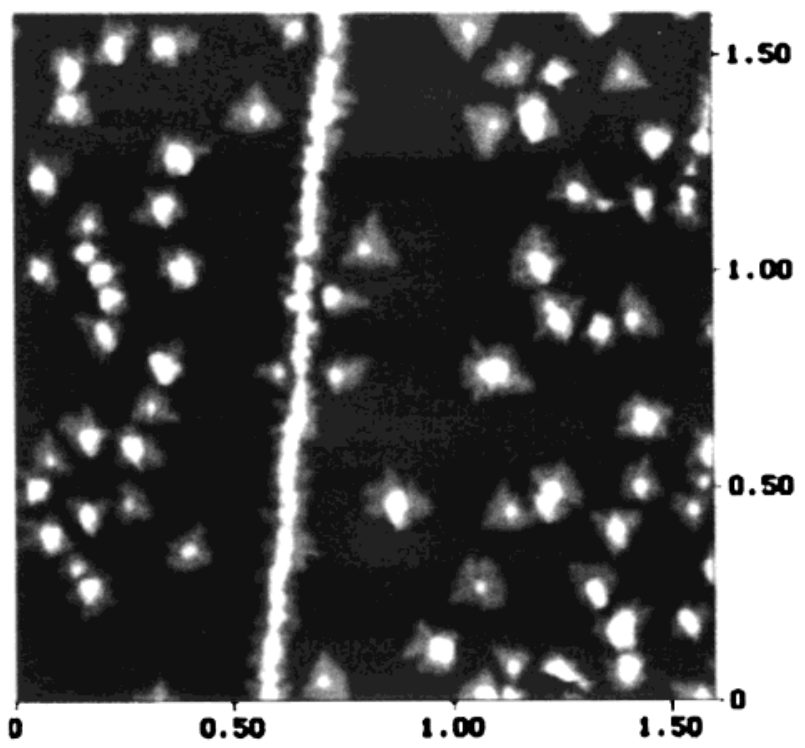

$\mu \mathrm{m}$ b

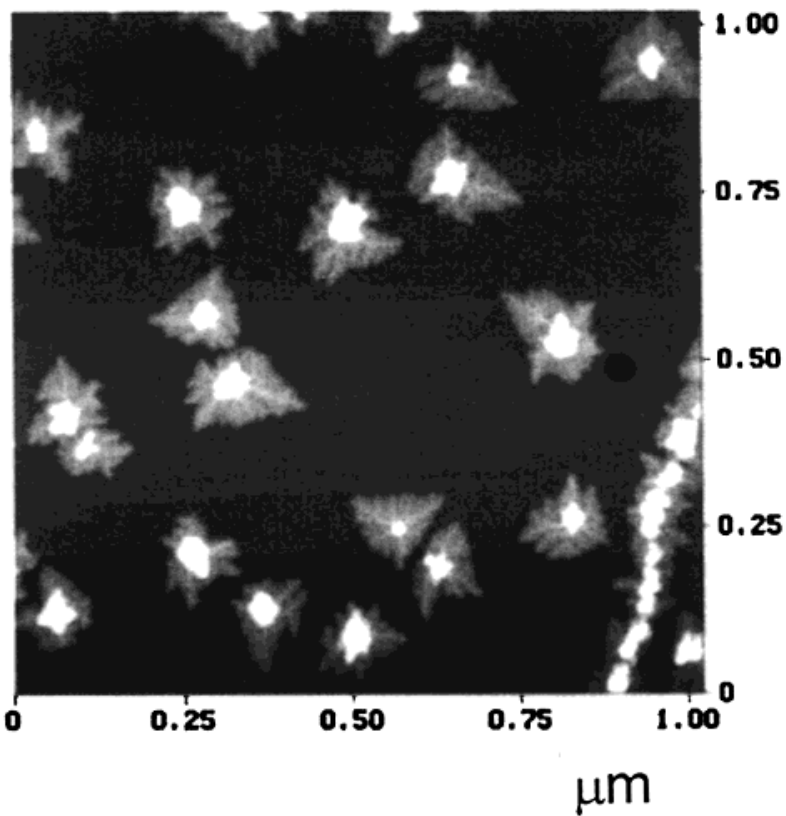

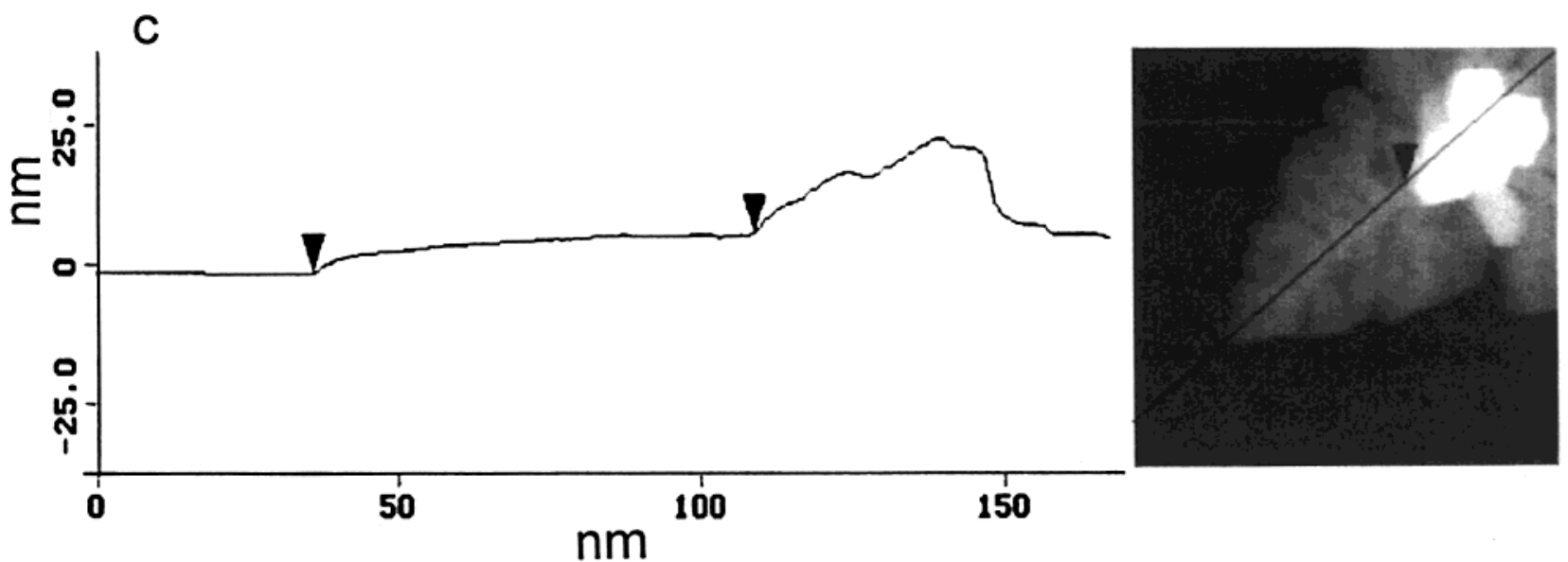

Figure 2. STM images (top view) for branched electrodeposited palladium islands $\left(q_{\mathrm{d}}=3 \mathrm{mC} / \mathrm{cm}^{2} \mathrm{HOPG}\right) \mathrm{produced}$ at $E_{\mathrm{d}}=$ $-0.100 \mathrm{~V}$ : (a) $1.6 \times 1.6 \mu \mathrm{m}^{2}$ and (b) $1.0 \times 1.0 \mu \mathrm{m}^{2}$. (c) Cross section of a single main branch of palladium electrodeposit.

polycrystalline platinum, which exhibits conjugated pairs of current peaks related to weakly and strongly bound hydrogen adatoms at ca. -0.05 and $-0.20 \mathrm{~V}$, respectively (Figure 4b), no hydrogen atom electroadsorption/electrodesorption voltammogram can be determined for smooth massive palladium electrodes.

Similar voltammetric runs were performed with nanometer-sized palladium islands of different morphologies supported on HOPG, namely, the quasi-hemispherical islands prepared at $E_{\mathrm{d}}=0.125 \mathrm{~V}\left(q_{\mathrm{d}}=5 \mathrm{mC} \mathrm{cm}^{-2}\right)$ (Figure $4 \mathrm{c}$ ) and branched islands produced at $E_{\mathrm{d}}=$ $-0.100 \mathrm{~V}\left(q_{\mathrm{d}}=5 \mathrm{mC} \mathrm{cm} \mathrm{cm}^{-2}\right)$ (Figure $\left.4 \mathrm{~d}\right)$. In constrast to massive palladium, both types of palladium islands exhibit voltammetric features resembling those for hydrogen atom electroadsorption/electrodesorption on platinum (Figure 4b). For palladium island electrodes, these processes are characterized by peaks I and II at ca. -0.25 and $-0.15 \mathrm{~V}$, respectively (Figure $4 \mathrm{c}$ ). In these cases, the voltammetric anodic-to-cathodic charge ratio approaches 1 , as would be expected for a relatively fast surface electrochemical reaction. ${ }^{24,25}$ It can also be observed that, for branched palladium islands, the peak
$\mathrm{I} /$ peak II charge ratio is also enhanced, as compared to that resulting from quasi-hemispherical islands. Therefore, the contribution of the reaction $\mathrm{Pd}(\mathrm{H})_{\mathrm{ad}}=\mathrm{Pd}+$ $\mathrm{H}^{+}+\mathrm{e}^{-}$, as compared to that of the hydrogen absorption reaction, appears to be considerably enhanced on nanometer-sized palladium islands on HOPG, particularly on those with a branched island morphology. It should be noted that a voltammogram obtained from a palladium-plated HOPG electrode $\left(E_{\mathrm{d}}=-0.100 \mathrm{~V}, q_{\mathrm{d}}\right.$ $=20 \mathrm{mC} \mathrm{cm}^{-2}$ ) (Figure $4 \mathrm{~d}$, dashed trace) exhibits a contribution of hydrogen electroadsorption/electrodesorption much smaller than that observed for branched palladium islands.

To confirm the high electrochemical reactivity of nanometer-sized branched palladium islands, we also investigated the electrochemical oxidation of hydrazine on massive palladium and on quasi-hemispherical and nanometer-sized branched palladium islands $\left(q_{\mathrm{d}}=5 \mathrm{mC}\right.$

(24) Srinivasan, S.; Gileadi, E. Electrochim. Acta 1966, 11, 321

(25) Baldauf, N.; Kolb, D. M. Electrochim. Acta 1993, 38, 2145 and references therein. 


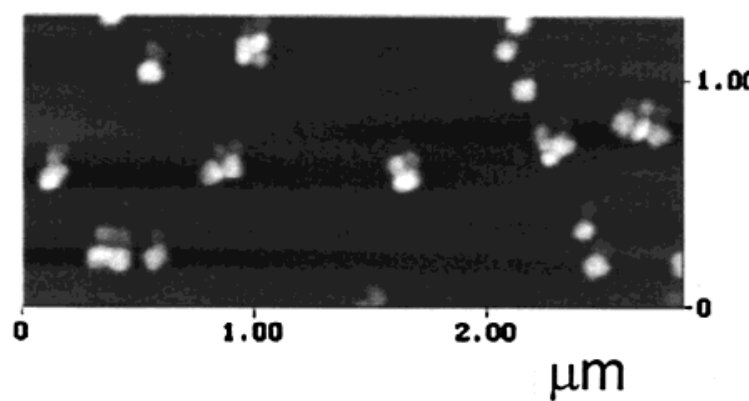

a

C
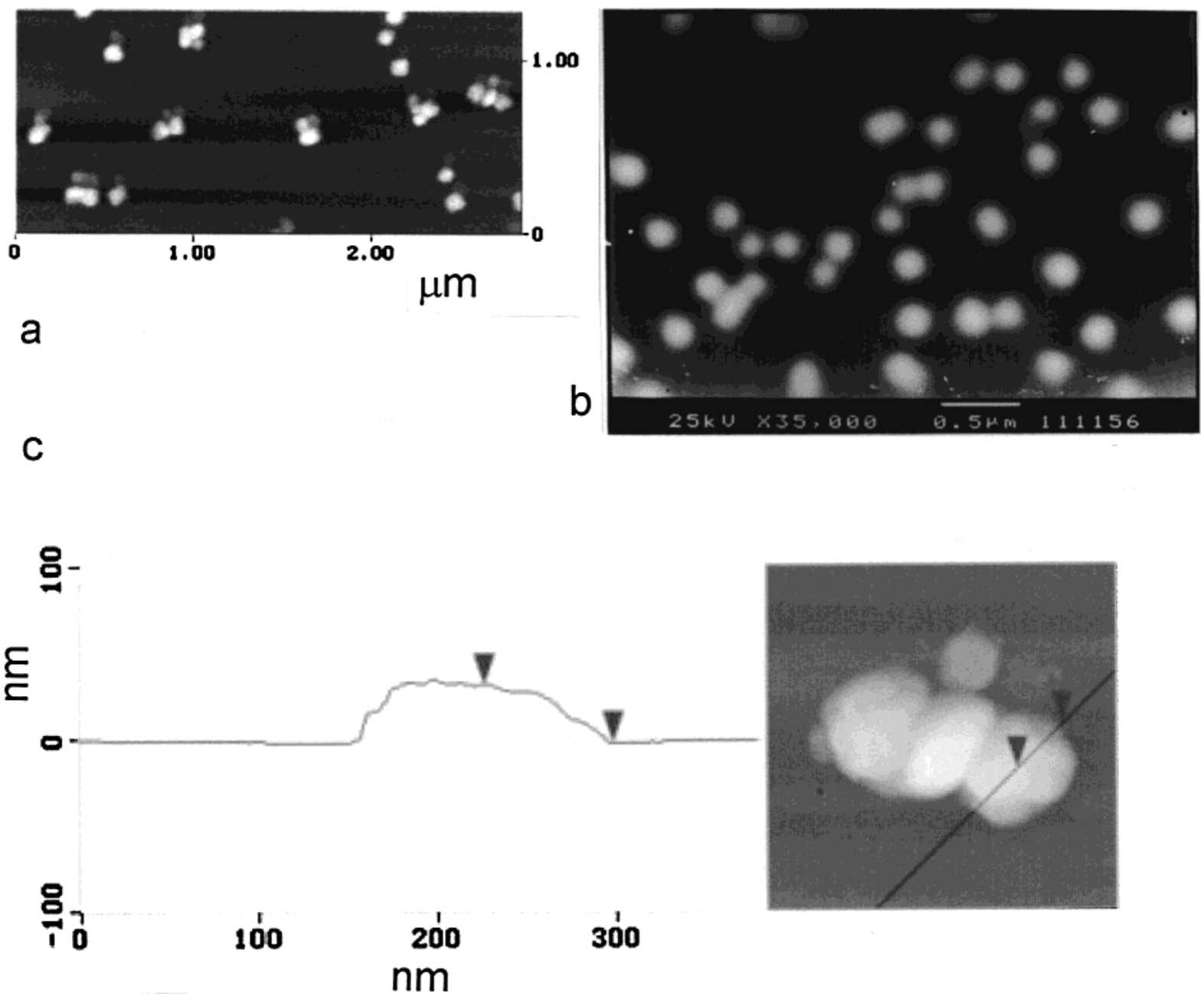

$\mathrm{nm}$

Figure 3. (a) STM image (top view) and (b) SEM micrograph for quasi-hemispherical electrodeposited palladium islands $\left(q_{\mathrm{d}}=\right.$ $3 \mathrm{mC} / \mathrm{cm}^{2}$ HOPG) produced at $E_{\mathrm{d}}=0.125 \mathrm{~V}$. (c) STM image and cross section of a quasi-hemispherical island grown as described in part a.

$\mathrm{cm}^{-2}$ ) supported on HOPG. For this purpose, an aqueous mixture of $6 \times 10^{-3} \mathrm{M}$ hydrazine and $0.1 \mathrm{M}$ potassium sulfate was employed, and the reaction was also followed voltammetrically. For massive palladium (Figure $5 a)$, the voltammogram shows a broad anodic current peak at $0.31 \pm 0.01 \mathrm{~V}$, which is related to the electrooxidation of hydrazinium ions. This peak is followed by another broad peak at ca. $0.6 \mathrm{~V}$, which corresponds to the formation of an oxygen-containing layer on palladium. This layer is electroreduced during the reverse potential scan, ${ }^{26}$ as seen by the broad current peak at ca. $0.5 \mathrm{~V}$. For a quasi-hemispherical palladium island produced at $E_{\mathrm{d}}=0.125 \mathrm{~V}$ (Figure $5 \mathrm{~b}$ ), the anodic current peak potential related to hydrazinium ion electrooxidation is $0.33 \pm 0.01 \mathrm{~V}$. For branched palladium islands (Figure 5c), the voltammetric peak potential related to hydrazinium ion electrooxidation is $0.26 \pm 0.01 \mathrm{~V}$. In this case, the conjugated cathodic reaction is also observed at the same potential during the reverse scan. Furthermore, the initial portion of the voltammogram fits a linear $E$ vs $\ln I$ plot, with a slope $\Delta E /(\Delta \ln I)$ that decreases from $0.15 \pm 0.01$ to $0.09 \pm 0.01 \mathrm{~V} / \mathrm{ln}$ unit in going from smooth palladium to branched palladium

(26) Bolzan, A. E.; Martins, M. E.; Arvia, A. J. J. Electroanal. Chem. 1984, 172, 221. Bolzan, A. E.; Chialvo, A. C.; Arvia, A. J. J. Electroanal. Chem. 1984, 179, 71. islands on HOPG. These results are consistent with electrochemical reaction kinetics dominated by intermediate control. ${ }^{27}$

Under the above-mentioned conditions, the electrochemical oxidation of hydrazine is a four-electron reaction: $\mathrm{N}_{2} \mathrm{H}_{5}{ }^{+}=\mathrm{N}_{2}+5 \mathrm{H}^{+}+4 \mathrm{e}^{-}$. The voltammogram of this reaction involves a pair of conjugated peaks at $0.26-0.33 \mathrm{~V}$, related to a complex electrochemical reaction that depends considerably on the crystallography, state, and history of the electrode surface, as has been concluded for platinum electrodes in the same solution. ${ }^{17,18}$ The decrease in the value of $\Delta E /(\Delta \ln I)$, the increase in height of conjugated peaks and the displacement of their peak potentials by $-0.07 \mathrm{~V}$ indicate an increased catalytic effect of nanometer-sized branched palladium island electrodes. Therefore, this electrode material behaves as the electrochemically most active material for both test reactions.

\section{Discussion}

4.1. Origin and Nature of the Branched Island Morphology. The electrochemical growth mode of metallic deposits on solid substrates depends on a

(27) Bard, A. J.; Faukner, L. Electrochemical Methods; John Wiley \& Sons: New York, 1980 

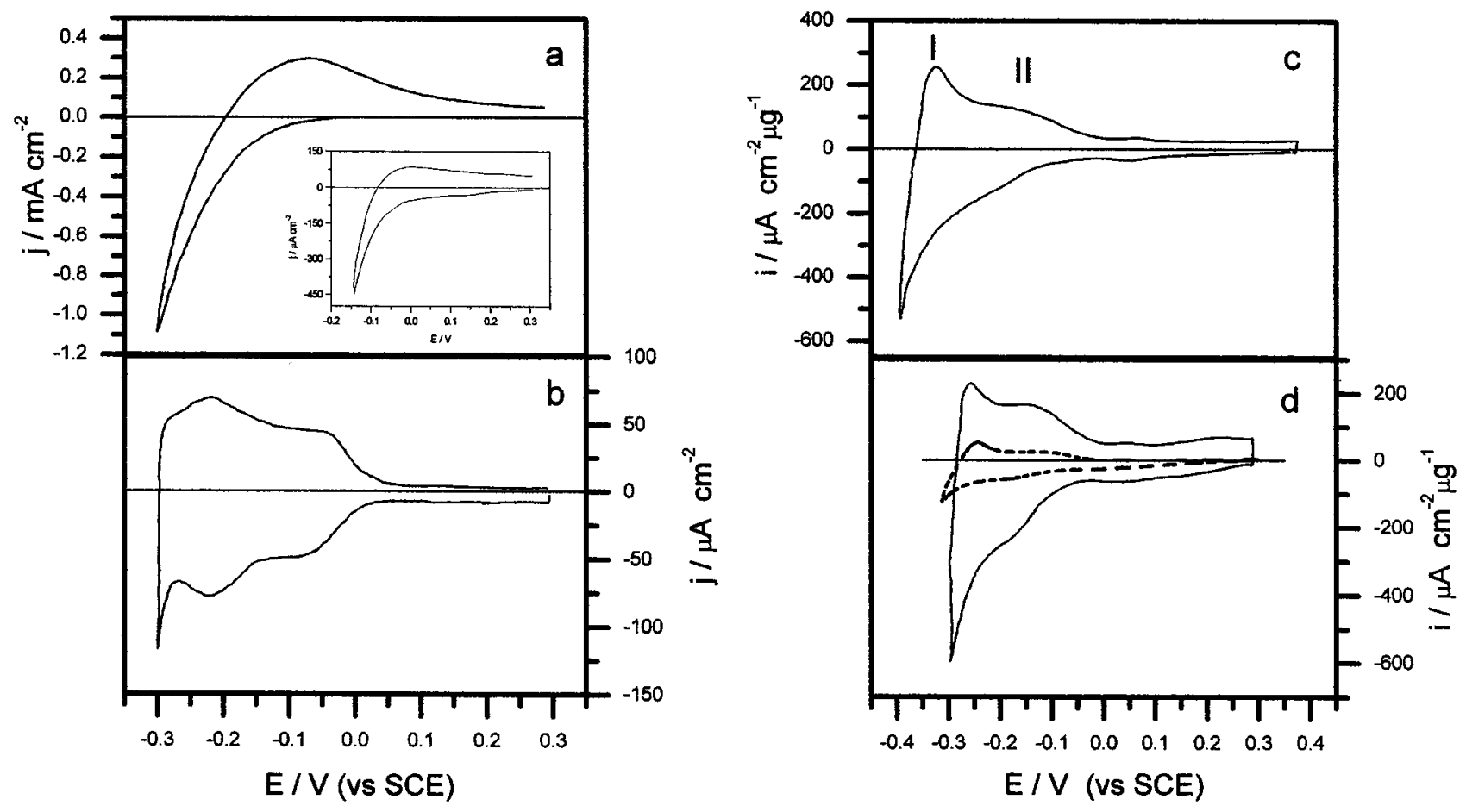

Figure 4. Current density/potential curves run at $0.1 \mathrm{~V} / \mathrm{s}$ in the potential range from 0.30 to $-0.30 \mathrm{~V}$ where hydrogen-atom electrosorption/electrodesorption reactions are observed on platinum. Aqueous $0.1 \mathrm{M}$ perchloric acid, $298 \mathrm{~K}$. (a) Polycrystalline palladium electrode $\left(0.125 \mathrm{~cm}^{2}\right.$ geometric area). The voltammogram (inset) corresponds to the cathodic potential limit of $-0.15 \mathrm{~V}$. (b) Polycrystalline platinum electrode $\left(0.08 \mathrm{~cm}^{2}\right.$ geometric area). (c) Quasi-hemispherical palladium islands on HOPG $\left(q_{\mathrm{d}}=5\right.$ $\left.\mathrm{mC} / \mathrm{cm}^{2}\right)$. (d) The continuous trace corresponds to branched palladium islands on HOPG $\left(q_{\mathrm{d}}=5 \mathrm{mC} / \mathrm{cm}^{2}\right)$. The dashed trace corresponds to a palladium-plated electrode $\left(E_{\mathrm{d}}=-0.1 \mathrm{~V}, q_{\mathrm{d}}=20 \mathrm{mC} / \mathrm{cm}^{2}\right)$.

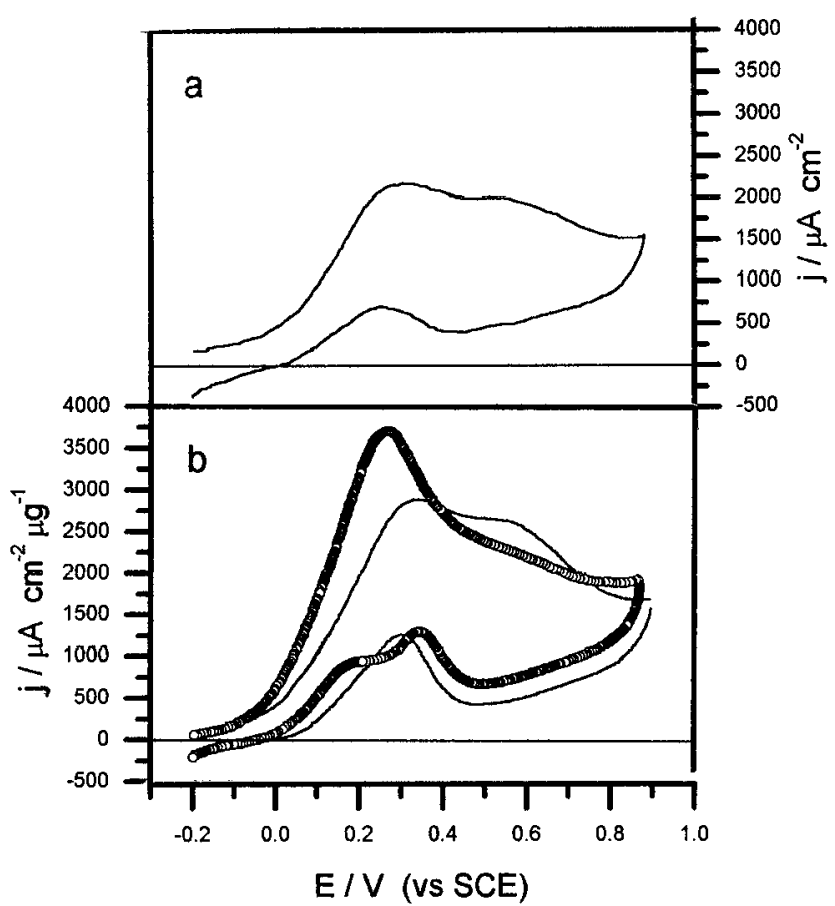

Figure 5. Current density vs potential curves for hydrazine electrooxidation run at $0.2 \mathrm{~V} / \mathrm{s}$. Aqueous $6 \times 10^{-3} \mathrm{M}$ hydrazinium sulfate and $0.1 \mathrm{M}$ potassium sulfate, $298 \mathrm{~K}$. (a) Polycrystalline palladium electrode. (b) Quasi-hemispherical (full trace) and branched (open circles) palladium islands on HOPG $\left(q_{\mathrm{d}}=5 \mathrm{mC} / \mathrm{cm}^{2}\right)$. The current density in Figure $5 \mathrm{~b}$ is also referred to the weight of electrodeposited palladium calculated from $q_{\mathrm{d}}$.

number of variables related to the flow rate of the electroactive species, the environmental conditions such as the nature of both the solution constituents and the substrate surface, and the electric and diffusional fields bound to the process. This ensemble of variables influences the local kinetics and mechanism of the electrodeposition process and determines, to a large extent, the morphology of the new solid phase at different scales. ${ }^{23,28}$

Surface processes at the atomic level depend on the sticking process of incoming electroactive species and coupled surface relaxation processes such as those resulting from surface tension effects and/or the surface diffusion of adatoms. ${ }^{23}$ The concurrence of these events in the overall process determines the growth mode of the new phase. Relaxation processes are strongly determined by the presence of adsorbable constituents in the solution. ${ }^{29}$ It is known that the contribution of chloride ions to the isotropic surface diffusion of metal adatoms in electrochemical deposition favors the development of rounded morphologies, particularly at the initial stages of growth. ${ }^{30}$

A general equation for the discharge of palladium species from our plating solution can be written as follows

$$
\left(\mathrm{PdCl}_{n}\right)^{2-n}+2 \mathrm{e}^{-}=\mathrm{Pd}^{0}+n \mathrm{Cl}^{-}
$$

with $n=0-4$. As the potential of zero charge for polycrystalline palladium is $E_{\mathrm{pzc}} / \mathrm{V}=0.010$ (vs SCE) at $298 \mathrm{~K},{ }^{31}$ for $E>E_{\mathrm{pzc}}$, electrodeposited palladium islands

(28) Martin, H.; Carro, P.; Hernández Creus, A.; González, S.; Salvarezza, R. C.; Arvia, A. J. Langmuir 1997, 13, 100.

(29) Garcia, M. P.; Gómez, M. M.; Salvarezza, R. C.; Arvia, A. J. J. Electroanal. Chem. 1993, 347, 237.

(30) Martin, H.; Carro, P.; Hernández Creus, A.; González, S.; Salvarezza, R. C.; Arvia, A. J. J. Phys. Chem. B 1999, 103, 3900.

(31) Frumkin, A. N.; Petrii, O. A. Electrochim. Acta 1975, 20, 347. 
are positively charged with respect to the solution, and therefore, the electrodeposition in region I occurs under a large concentration of adsorbed chloride ions on the surface and chloride-ion-containing palladium ions at the reaction interface. As for platinum electrodeposition from platinum chloride complexes, ${ }^{32}$ the electrodeposition of palladium in region I likely follows a complex mechanism in which chemical and electrochemical steps involving intermediate species such as $\mathrm{PdCl}_{3}{ }^{-}, \mathrm{PdCl}_{2}$, and $\mathrm{PdCl}^{+}$should be considered. ${ }^{20}$ Accordingly, as has been extensively discussed in recent publications, ${ }^{27-30}$ a strong influence of chloride-ion-inducing isotropic surface relaxation of attaching palladium atoms should be expected. ${ }^{27,30}$ This fact results in the formation of islands with a rounded morphology from palladium electrodeposition in region I. Gold electrodeposits with a similar morphology under comparable operation conditions have been produced on HOPG. ${ }^{28}$

The above situation changes when we enter the potential range where reaction 1 occurs for $E_{\mathrm{d}} \approx E_{\mathrm{pzc}}$. In this case, the anion-island surface interaction energy diminishes, although the surface concentration of adsorbed chloride ions assisted by reaction 1 remains sufficiently high to maintain the isotropic surface relaxation of depositing ions favoring a pseudo-hemispherical morphology clustering into small rounded islands at $E_{\mathrm{d}}=0.125 \mathrm{~V}$ (Figure 3).

Finally, for $E_{\mathrm{d}}=-0.100 \mathrm{~V}$, i.e., $E<E_{\mathrm{pzc}}$, the electrode surface is negatively charged with respect to the solution, and the strong anion-island surface repulsive interactions make the surface concentration of adsorbed chloride ions approach zero. Then, the isotropic surface relaxation of depositing ions at growing islands will be practically prevented, and as a result, the anisotropic surface displacement of palladium atoms will play a dominant kinetic role. Consequently, the rate of displacement of these atoms toward sites at the growing phase should be determined by the heights of the energy barriers for surface diffusion located at terraces, step edges, and corners. ${ }^{33}$ In fact, this implies a change in the physical mechanism of palladium phase growth.

In conclusion, the different growth modes of palladium islands are consistent with the physicochemical mechanisms that have been extensively discussed for the formation of new solid phases by different procedures, including electrochemical deposition. ${ }^{23}$ In this way, we can understand why the geometry of the growth patterns changes from Euclidean to fractal as $E_{\mathrm{d}}$ is shifted negatively. A similar interpretation has been advanced to explain the change from a Euclidean to a fractal perimeter of electrodeposited gold islands on HOPG ${ }^{28}$ Finally, as far as the role of the susbstrate is concerned, it should be noted that branched fractal metallic islands have also been grown from the vapor phase on other substrates with hexagonal symmetries such as gold on $\mathrm{Ru}(0001)^{34}$ and silver on $\mathrm{Pt}(111) .{ }^{33}$

4.2. Electrocatalytic Effects. The enhancement of hydrogen electroadsorption/electrodesorption observed for both the quasi-hemispherical and branched palladium islands resembles the enhancements of the same reactions that have been observed for palladium mono-

(32) Kravtsov, V. I. Russ. J. Electrochem. 2000, 11, 1209.

(33) Brune, H.; Roder, H.; Bromann, K.; Kern, K.; Jacobsen, J.; Norskov, J. Surf. Sci. 1996, 76, L115. layers deposited on a foreign substrate ${ }^{25}$ and on fractal surfaces of palladium grown by the electroreduction of palladium oxides. ${ }^{16}$ This type of fractal deposit exhibits a large surface/volume ratio because of its porous structure. Therefore, it is reasonable to assume that the large surface/volume ratio of the islands determines the enhancement of the hydrogen atom electroadsorption/ electrodesorption surface processes in relation to bulk processes such as hydrogen absorption. ${ }^{16}$ This can explain, on one hand, the voltammetric behavior of massive, quasi-hemispherical and branched palladium islands shown in Figure 4 and, on the other hand, the enhancement of hydrogen electroadsorption/electrodesorption reactions in going from quasi-hemispherical island electrodes with Euclidean perimeters to branched palladium island electrodes with fractal perimeters.

In principle, the main effects converging to the electrocatalytic enhancement for hydrazine electrooxidation observed for branched palladium islands can be related to a decrease in the resistance of the electrochemical reaction produced either by the effective island size or by a specific structure and energy distribution at the metal surface.

The distribution of a large number of small islands on a smooth substrate would be equivalent to an array of microelectrodes, as recently described for platinum columnar-structured surfaces. ${ }^{35}$ For such a situation, the kinetics of the electrochemical reaction would be almost free of ohmic-drop effects and mass-transport limitations. ${ }^{36}$ However, considering that there is a remarkable difference in the catalytic activity between branched and quasi-hemispherical palladium island electrodes produced at the same $q_{\mathrm{d}}$ and number density and almost the same average island size, it appears that this explanation does not completely account for the behavior of these materials. Most likely, for nanometersized islands, geometrical factors have a strong influence on the local electronic structure and surface energy distribution at the metal surface. These last two effects are influenced by the presence of different facets with specific chemical reactivities. ${ }^{37}$ In fact, the growth of branched metal deposits is usually associated with the development of the most compact atomic arrangements, such as (111) terraces and (111) stepped terraces. In principle, this is consistent with recent density functional calculations of the chemical reactivity of palladium clusters. ${ }^{38}$

The real surface area of nanometer-sized branched palladium islands is very difficult to evaluate because of their morphology and size distribution. However, considering voltammetric data from both test reactions on palladium island electrodes prepared over the range $1 \mathrm{mC} \mathrm{cm}{ }^{-2} \leq q_{\mathrm{d}} \leq 5 \mathrm{mC} \mathrm{cm}{ }^{-2}$, the catalytic effect appears to be related mainly to a surface reactivity that should depend largely on the type and concentration of

(34) Hwang, R. Q.; Schroder, J.; Gunther, C.; Behm, R. Phys. Rev. Lett. 1991, 67, 3279 .

(35) Martins, M. E.; Rodríguez Nieto, F. J.; Salvarezza, R. C.; Andreasen, G.; Arvia, A. J. J. Electroanal. Chem. 1999, 477, 14.

(36) Scharifker, B. R. In Modern Aspects of Electrochemistry; Bockris, J. O’M., Conway, B. E., White, R. E., Eds.; Plenum Press: New York, 1992; Vol. 22, p 467.

(37) Triaca, W. E.; Arvia, A. J. J. Appl. Electrochem. 1990, 20, 347 and references therein.

(38) Bertani, V.; Cavallotti, C.; Masi, M.; Carrá, S. J. Phys. Chem. $A$ 2000, 104, 11390. 
surface defects, i.e., on the ratio between the number of palladium surface atoms and the total number of electrodeposited palladium atoms on HOPG $\left(R_{S / V}\right)$, i.e., on the fractal perimeter of islands.

Let us attempt to compare the electrocatalytic behavior of nanometer-sized branched palladium islands on HOPG considering quasi-hemispherical islands produced for $q_{\mathrm{d}}=5 \mathrm{mC} \mathrm{cm} \mathrm{cm}^{-2}$ as an arbitrary reference. For this purpose, the geometrical descriptions of quasihemispherical islands produced at $0.125 \mathrm{~V}$ and of branched islands formed at $-0.100 \mathrm{~V}$ are approached in terms of smooth Euclidean hemispheres and fractal objects, respectively, using the average dimensions derived from STM imaging. Thus, for hemispherical palladium islands with a 77.5-nm average radius, the number of electrodeposited palladium atoms is $1.56 \times$ $10^{16} \mathrm{~cm}^{-2}$, and the density of nuclei determined from the STM images is $5.8 \times 10^{9} \mathrm{~cm}^{-2}$. Correspondingly, each island, with a $3.8 \times 10^{-10} \mathrm{~cm}^{2}$ surface area and a $9.8 \times 10^{-16} \mathrm{~cm}^{3}$ volume, consists of $2.7 \times 10^{8}$ atoms. Taking into account the atomic volume of palladium, $1.47 \times 10^{-23} \mathrm{~cm}^{3}$, and the surface atom density of smooth palladium, $1.3 \times 10^{15} \mathrm{~cm}^{-2}$, this results in $R_{S / V}$ $\approx 0.01$. This value implies a relatively large cluster of atoms with electronic surface properties close to those of bulk palladium. In constrast to pseudo-hemispherical islands, branched palladium islands behave as fractal objects, an indication of strongly disordered regions at island surfaces. ${ }^{39}$ Therefore, as a consequence of the large number of surface defects, the local value of $R_{S / V}$ would be appreciably increased compared to that for pseudo-hemispherical islands. In fact, branched pattern tips less than $10 \mathrm{~nm}$ in radius (Figure 2) can be considered as a collection of nanometer-sized clusters of about $10^{5}$ atoms, yielding $R_{S / V} \approx 0.1$. Then, the local electronic properties become different from those predicted on the basis of data for extended surfaces, which leads to size effects in heterogeneous catalysis. ${ }^{3}$ This is a reasonable explanation for the increase in current ratio by $26 \pm 2 \%$ in going from pseudo-hemispherical to branched island electrodes.

In conclusion, we present an electrochemical method for the growth of stable quasi-2D branched palladium islands on HOPG. These islands show a considerable enhancement of their electrocatalytic properties for two basically different electrochemical reactions that are of practical interest. This enhancement is related to the radial morphology of islands with fractal perimeters.

Acknowledgment. This paper was financially supported by PIP 0897/98 and PIP 4376 from CONICET (Argentina), PICT 99-5030 and PICT 03251/98 from Agencia Nacional de Promoción Científica y Técnológica (Argentina), and Project 1999/128 from Gobierno Canario (Spain). Y.G.'s fellowship grant from Gobierno Canario (Spain) is also acknowledged.

CM0100164

(39) Avnir, D., Ed. The Fractal Approach to the Heterogeneous Chemistry, John Wiley \& Sons: New York, 1989. 